Institute of $\mathbf{F}_{\text {ood and }} \mathbf{A}_{\text {gricultural }} \mathbf{S}_{\text {ciences }}$

\title{
Manual de los Reglamentos del Agua de Florida: Manejo y Almacén de Aguas Superficiales ${ }^{1}$
}

\author{
Michael T. Olexa, Laura Minton, Dulcy Miller, y Sarah Corbett ${ }^{2}$
}

\section{Agradecimientos}

Los autores agradecen a Richard Budell de la Oficina de Política del Agua Agrícola del Departamento de Agricultura y Servicios al Consumidor de Florida. Los autores también agradecen a David H. Hammonds, Consultor del Programa de Salud Ambiental, Oficina de Programas de Aguas de Drenaje en el Sitio, del Departamento de Salud de Florida, y a Edward A. Bettinger, Consultor del Programa de Salud Ambiental, Oficina de Programas de Agua del Departamento de Salud de Florida.

\section{¿Quien Regula el Manejo y Almacén de Aguas Superficiales?}

Para prevenir el daño a las aguas del estado, las juntas gobernantes de los distritos de manejo de agua (DMA) y el Departamento de Protección Ambiental (DPA) están investidos con la autoridad para exigir permisos para el manejo y almacén de aguas superficiales( permisos MAAS) e imponer condiciones sobre esos permisos. Esta autoridad esta delegada casi totalmente a los DMAs, quienes deberán ser consultados antes de llevar a cabo cualquier alteración de aguas superficiales.

1. Este es el documento EDIS FE082, una publicación del Department of Food and Resource Economics, Florida Cooperative Extension Service, Institute of Food and Agricultural Sciences, University of Florida, Gainesville, FL. Publicada Noviembre 2002. Por favor visite la página electrónica EDIS en http://edis.ifas.ufl.edu.

2. Michael T. Olexa, es profesor del Department of Food and Resource Economics, Florida Cooperative Extension Service, Institute of Food and Agricultural Sciences, University of Florida, Gainesville, FL; y miembro de Florida Bar; Presidente de Agricultural Law Committee of The Florida Bar; y Director del Agricultural Law Center. Laura Minton, Dulcy Miller, y Sarah Corbett son estudiantes graduadas de Levin College of Law, University of Florida, Gainesville, FL. Filiberto Reyes-Villanueva fue el traductor de la versión en ingles al español.

Esta publicación esta diseñada para proporcionar información precisa, actualizada y autorizada sobre esta material. Sin embargo, ya que las leyes, reglas administrativas y decisiones de la corte, sobre las cuales están basados, están sujetas a revisión constante; algunas partes de esta publicación podrían ser obsoletas en cualquier momento. Esta publicación es distribuida bajo el entendimiento que los autores no están involucrados en ninguna representación legal u otros servicios profesionales, y que la información contenida aquí no debe ser considerada como un substituto de una asesoria legal. Esta publicación no esta completa en proporcionar toda la información para lograr el cumplimiento de las leyes y reglamentos que gobiernan la protección del agua. Por estas razones, el uso de estos manuales por cualquier persona constituye un acuerdo para mantener libre de daño a los autores, al Florida Cooperative Extension Service, al Institute of Food and Agricultural Sciences, y a la University of Florida por cualquier demanda por responsabilidad de daños, o gastos en que pueda incurrir cualquier persona, como un resultado de hacer referencia o confianza sobre la información contenida en esta publicación. Esta publicación fue apoyada financieramente por el Florida Department of Agriculture and Consumer Services.

EI Instituto de Alimentos y Ciencias Agrícolas es Un empleador que opera bajo Acción Afirmativa y provee Oportunidades Igualitarias, dedicado a promocionar la investigación, a información educativa y otros servicios, únicamente a los individuos e instituciones que operan baj discriminación sin considerar color, raza, sexo, edad, incapacidad u origen. Para más información sobre como obtener otras publicaciones de la extensión, comuníquese con la oficina de Servicio de Extensión de su condado. Servicio de Extensión de la Florida / Instituto de Alimentos y Ciencias Agrícolas / Universidad de la Florida / Christine Taylor Waddill, Decana. 


\section{¿Qué Incluye el MAAS?}

El enfoque de los estatutos y reglas que gobiernan el manejo de las aguas superficiales se extiende básicamente a la construcción, operación o alteración de cualquier "sistema de manejo de aguas de lluvia, represa, estanque, reservorio, o trabajos accesorios". Las definiciones estutarias de estos términos generalmente contribuyen a una capacidad tal, que pueden colectivamente regular virtualmente todos los tipos de estructuras naturales $o$ construcciones artificiales, que puedan ser usadas para conectar, extraer agua, drenar agua dentro de, o ser colocadas en o a través de aguas superficiales. En esencia, ello incluye todas las estructuras y construcciones que pueden tener efecto en la superficie del agua. Estas incluyen las siguientes:

- dragado.

- rellenado.

- actividades que formen canales, acequias, drenes, represas, caminos inundados, construcciones y otras superficies impermeables.

\section{¿Cuáles son las Exenciones?}

Para evitar poner requerimientos excesivamente rigurosos en los permisos para los granjeros, el estatuto contiene una exención calificada. Las personas involucradas en el trabajo de agricultura, silvicultura, floricultura u horticultura, pueden alterar cualquier pedazo de tierra sin un permiso MAAS, siempre que las practicas sean actividades normales de trabajo, cuyo único y predominante propósito no sea el de obstruir o posesionarse de aguas superficiales. Estas actividades incluyen las siguientes:

- preparación del sitio, limpieza, cercado nivelación para prevenir la erosión del suelo.

- preparación del suelo, arado, siembra o cosecha.

La exención es calificada en que la represa $u$ obstrucción de las aguas superficiales pueden no tener el principal objetivo de la alteración. La construcción o mantenimiento hecho en diques, presas o embalses en un sistema agrícola cerrado, será exento de permisos MAAS (Sistema cerrado significa un sistema de irrigación auto-mantenido, usado en agricultura y que no tiene descargas hacia el exterior). No obstante, estos trabajos deben aun cumplir con los estándares de ingeniería. Donde la ingeniería es regulada por el estado, esto puede requerir la certificación apropiada del proyecto y un apego estricto a los planes originales.

Es siempre aconsejable consultar con el distrito especifico cuando se intenta determinar si una actividad propuesta esta exenta, ya que en ocasiones se requiere de una notificación escrita por el DPA o DMA.

\section{¿Qué Permisos son Requeridos?}

Ciertos DMAs deben contar con el concepto de "umbral"para determinar cuando un permiso es

exigido. Por ejemplo, una vez que una cierta cantidad de agua ha sido represada por una actividad o un proyecto de cierto tamaño, el DMA requerirá un permiso, a menos que la actividad este exenta por alguna razón. Aunque las excepciones establecidas por la ley se aplican en todos los cinco DMAs, los permisos de umbrales y excepciones adoptadas por reglamento variaran de un distrito a otro. La calidad del agua y las consideraciones de la cantidad, así como lo concerniente al medio ambiente en general, serán dirigidos en el proceso de aplicación para un permiso MAAS.

Con otros tipos de permisos, la revocación o modificación del permiso MAAS puede ocurrir si las condiciones del permiso o los mandatos no son cumplidos.

\section{¿Qué Debe ser Mostrado para Ser Elegible para un Permisos MAAS?}

Al nivel mas básico, el solicitante debe mostrar lo que ha sido planeado no será dañino para los recursos del agua. Y el aplicante también deberá mostrar que la actividad planeada no será inconsistente con los objetivos del DMA. En otra palabras, la actividad no puede estar en contra de los intereses públicos. 
Si la actividad planeada degradara significativamente la calidad del agua, el solicitante puede aun obtener un permiso. El solicitante debe mostrar que la actividad planeada estará clara para el interés del publico. Para determinar si una actividad planeada es no es contraria al interés publico, o es claramente para el interés publico, hay siete básicos criterios que deben están balanceados:

- si la actividad afectara adversamente la salud publica y la seguridad de otros.

- si la actividad afectara adversamente a los peces y la conservación de vida silvestre.

- si la actividad afectara adversamente la navegación o el flujo de agua.

- actividad afectara adversamente la pesca o valores recreacionales en el área de actividad.

- si la actividad es permanente o temporal por naturaleza.

- si la actividad afectara adversamente o mejorara los recurso importantes históricos y arqueológicos.

- la condición actual y valor de las actividades que ocurren en el área serán afectadas por la actividad planeada.

Si el aplicante tiene problemas para cumplir los criterios del DMA, el aplicante puede aun obtener un permiso a través de la mitigación.

\section{¿Qué son la Mitigación y Reparación de Mitigación?}

Mitigación es la creación, mantenimiento o restauración de un agua superficial a cambio de la degradación de otra área. Si alguien planea una actividad que degradara la superficie del agua en el area de actividad, esa persona puede aun obtener un permiso. Pero, el aplicante mitigara el daño creando o restaurando otra área.

\section{¿Cuáles son los Castigos?}

Aparte de la modificación y cancelación de permisos, los DMAs tiene el poder para imponer penalidades civiles de hasta $\$ 10,000$ por ofensa, por día por el mal manejo del agua superficial en violación de los estatutos o condiciones del permiso. Además, las violaciones intencionales delos estatutos pueden ser un delito de segundo grado, siendo la causa tanto de prisión como de fuertes multas.

\section{¿Se Requieren Otros Permisos?}

Independientemente de los requerimientos de permisos del MAAS para el manejo de aguas de superficie, otros permisos pueden ser necesarios. Por ejemplo, las disposiciones del permiso para el consumo aplican a la toma y descarga de agua para llenar, rellenar y mantener el nivel del agua en un sistema agrícola cerrado (ver la sección de Uso de Consumo). También, los proyectos de construcción de un dique con umbral inferior (un dique que existe bajo la línea de agua) puede necesitar de un permiso para llenado. Cualquier permiso requerido para llenado involucraría consideraciones y reglamentaciones federales de pantanos (ver la sección de Actividades en Pantanos).

Después que el permiso es aprobado, seguir ciertas practicas del mejor manejo, es una excelente manera de ayudar a asegurar la continuidad del cumplimiento de los reglamentos del gobierno (ver la sección Practicas del Mejor Manejo). Los ejemplos incluyen establecer franjas de amortiguamiento y zonas de manejo a los lados y alrededor de un sistema, manteniendo corrientes y alcantarillas que no afecten las corrientes arriba o abajo de una alcantarilla y una construcción cuidadosa de acceso a los caminos.

\section{Fuentes}

Estatutos de Florida sección 373.403-459;Titulo 40, Código Administrativo de Florida (reglas individuales de DMA).

\section{Contactos de Información}

S-1 